\title{
The Prognostic Significance of Neutrophil to Lymphocyte Ratio (NLR), Monocyte to Lymphocyte Ratio (MLR) and Platelet to Lymphocyte Ratio (PLR) on Long-Term Survival in Off-Pump Coronary Artery Bypass Grafting (OPCAB) Procedures
}

\author{
Tomasz Urbanowicz ${ }^{1, *(}$, , Anna Olasińska-Wiśniewska ${ }^{1}{ }^{1}$, Michał Michalak $^{2}{ }^{\circledR}$, Michał Rodzki ${ }^{1}$, \\ Anna Witkowska ${ }^{1}$, Ewa Straburzyńska-Migaj ${ }^{3}$, Bartłomiej Perek ${ }^{1}$ 通 and Marek Jemielity ${ }^{1}$ \\ 1 Cardiac Surgery and Transplantology Department, Poznan University of Medical Sciences, \\ 61-848 Poznan, Poland; anna.olasinska@poczta.onet.pl (A.O.-W.); michal.rodzki@skpp.edu.pl (M.R.); \\ anna.witkowska@skpp.edu.pl (A.W.); bperek@ump.edu.pl (B.P.); mjemielity@poczta.onet.pl (M.J.) \\ 2 Department of Computer Science and Statistics, Poznan University of Medical Sciences, \\ 60-806 Poznan, Poland; michal@ump.edu.pl \\ 3 1st Cardiology Department, Poznan University of Medical Sciences, \\ 61-848 Poznan, Poland; ewa.straburzynska-migaj@skpp.edu.pl \\ * Correspondence: tomasz.urbanowicz@skpp.edu.pl; Tel.: +48-61-854-9210
}

check for

updates

Citation: Urbanowicz, T.; OlasińskaWiśniewska, A.; Michalak, M.; Rodzki, M.; Witkowska, A.; Straburzyńska-Migaj, E.; Perek, B.; Jemielity, M. The Prognostic Significance of Neutrophil to Lymphocyte Ratio (NLR), Monocyte to Lymphocyte Ratio (MLR) and Platelet to Lymphocyte Ratio (PLR) on Long-Term Survival in Off-Pump Coronary Artery Bypass Grafting (OPCAB) Procedures. Biology 2022, 11, 34. https://doi.org/10.3390/ biology11010034

Academic Editor: Guo-Chang Fan

Received: 26 November 2021

Accepted: 22 December 2021

Published: 27 December 2021

Publisher's Note: MDPI stays neutral with regard to jurisdictional claims in published maps and institutional affiliations.

Copyright: (C) 2021 by the authors. Licensee MDPI, Basel, Switzerland. This article is an open access article distributed under the terms and conditions of the Creative Commons Attribution (CC BY) license (https:// creativecommons.org/licenses/by/ $4.0 /)$
Simple Summary: Inflammatory processes are involved in the development and progression of coronary artery disease. Environmental factors, including hyperglycaemia, hyperlipidaemia, or smoking, promote endothelial disfunction. This process generates inflammation, which further exaggerates vascular wall injury. Immune cells migrate to the endothelium after its damage and promote platelets activation. Cardiac surgery activates inflammatory response. The knowledge on the intensity of immune cells activation may enable assessment of long-term consequences, including increased morbidity and mortality. The off-pump coronary artery bypass grafting technique allows to minimize systemic inflammatory reaction; however, some extent of the response still exists and may influence surgical results. The assessment of inflammatory response has undeniable value in coronary artery disease management. Several markers have been proposed; however, indices widely available from whole blood count are most valuable in daily practice. We evaluated and proposed the use of neutrophil to lymphocyte ratio (NLR), monocyte to lymphocyte ratio (MLR), and platelets to lymphocyte ratio (PLR) in the prognosis of the long-term outcomes after off-pump coronary artery bypass grafting. Patients who present with abnormally increased values of pre-operative and post-operative NLR, MLR, and PLR should undergo meticulous follow-up controls, as they are burdened with a higher risk of death.

\begin{abstract}
Background: Cardiovascular diseases, apart from commonly known risk factors, are related to inflammation. There are several simple novel markers proposed to present the relation between inflammatory reactions activation and atherosclerotic changes. They are easily available from whole blood count and include neutrophil to lymphocyte ratio (NLR), monocyte to lymphocyte ratio (MLR), and platelets to lymphocyte ratio (PLR). The RDW results were excluded from the analysis. Method and results: The study based on retrospective single-centre analysis of 682 consecutive patients (131 (19\%) females and $551(81 \%)$ males) with median age of 66 years $(60-71)$ who underwent offpump coronary artery bypass grafting (OPCAB) procedure. During the median $5.3+/-1.9$ years follow-up, there was a $87 \%$ cumulative survival rate. The laboratory parameters including preoperative MLR > 0.2 (HR 2.46, 95\% CI 1.33-4.55, $p=0.004$ ) and postoperative NLR > 3.5 (HR 1.75, $95 \%$ CI 1.09-2.79, $p=0.019$ ) were found significant for long-term mortality prediction in multivariable analysis. Conclusion: Hematological indices NLR and MLR can be regarded as significant predictors of all-cause long-term mortality after OPCAB revascularization. Multivariable analysis revealed preoperative values of MLR $>0.2$ and postoperative values of NLR $>3.5$ as simple, reliable factors which may be applied into clinical practice for meticulous postoperative monitoring of patients in higher risk of worse prognosis.
\end{abstract}


Keywords: off-pump coronary artery bypass grafting; neutrophil to lymphocyte ratio; monocyte to lymphocyte ratio; platelets to lymphocyte ratio

\section{Introduction}

Cardiovascular diseases, apart from commonly known genetic, environmental, and behavioral risk factors, are related to inflammation [1-3]. Inflammatory cells and signaling pathways are pathological cornerstones of atherosclerosis development and progression [4]. The immunometabolism presents an interplay between metabolic diseases and inflammatory reactions [5].

The assessment of inflammatory response has undeniable value in coronary artery disease management. There are several simple novel markers proposed to present the relation between inflammatory reactions activation and atherosclerotic changes. They are easily available from the whole blood count and include neutrophil to lymphocyte ratio (NLR), monocyte to lymphocyte ratio (MLR), and platelets to lymphocyte ratio (PLR) [6-9].

MLR was postulated as an independent risk factor for coronary artery severity including future cardiovascular events [9]. NLR was reported as independent risk factor for severity of coronary lesions and predictor of adverse clinical outcomes, especially of acute coronary syndromes [10]. PLR was found as a predictor of atherosclerosis severity in stable coronary disease [11].

Surgical interventions activate inflammatory system response and may induce a chain of reactions that have an influence on patients' survival [12-14]. The utility of aforementioned ratios in surgical interventions was presented in previous studies [15-21].

Several studies have proved excellent long-term results of surgical revascularization for complex coronary artery disease [22-25]. The superior effect of coronary artery bypass grafting is related to arterial revascularization, despite the fact that systemic inflammatory activation triggered by cardiopulmonary bypass is present [26-29]. The off-pump coronary artery bypass grafting (OPCAB) was found to be a reliable option [29]. OPCAB technique allows to omit or minimize systemic inflammatory reaction syndrome (SIRS) related to extracorporeal circulation utility [30-32]. Still, however, some extension of inflammatory reaction occurs during surgical interventions and lasts for 24-48 $\mathrm{h}$ [33].

The aim of the study was to compare presented hematological indices and long-term mortality risk in patients undergoing off-pump coronary artery bypass grafting.

\section{Materials and Methods}

The analysis including NLR, MLR, and PLR was conducted in a registry-based study performed in as single-center analysis of 682 patients who underwent off-pump coronary artery bypass grafting (OPCAB) at an experienced academic center in Poland. All participants of the study were referred for surgical revascularization of multivessel coronary atherosclerosis and were qualified for elective coronary artery bypass grafting (CABG) by the heart team $[34,35]$. The trial was conducted in accordance with the principles of Good Clinical Practice and the Declaration of Helsinki and approved by the Local Ethics Committee of Medical University of Poznan (approval number: 914/21). All participants were provided written informed consent.

The exclusion criteria involved patients requiring complex procedure including either concomitant valve disease requiring surgical intervention or aortic aneurysms, patients referred for surgery with acute nonST-elevation (NSTEMI) and ST-elevation (STEMI) myocardial infarction, and end-stage kidney disease requiring hemodialysis. In addition, patients affected by active or chronic inflammatory or autoimmune diseases, and steroid therapy or presenting active or past hematological proliferative diseases or oncological history were excluded as well. Patients with incomplete preoperative medical records, including whole blood count laboratory results, were disqualified. 
There were standardized definitions for collecting clinical information from electronic medical records as demographics, patients' comorbidities, available laboratory data, applied pharmacotherapy, recorded echocardiographic data, surgical details, and in-hospital outcomes were used. Preoperative hematological indices including NLR, MLR, and PLR were determined on day 1 before surgery (baseline value). NLR was calculated as neutrophils number divided by the number of lymphocytes, MLR as the number of monocytes divided by the number of lymphocytes, and PLR as the number of platelets divided by the number of lymphocytes. Postoperative NLR, MLR, and PLR were determined on first postoperative day following surgery. The RDW (red cells distribution width) results were excluded from the analysis. The other inflammatory parameters, such as C-reactive protein (CRP) or procalcitonin, were not routinely assessed.

The numbers of neutrophils, monocytes, and platelets to lymphocytes for NLR, MLR, and PLR assessment were collected by a routine hematology analyzer (Sysmex Europe $\mathrm{GmbH}$, Norderstedt, Germany). Other laboratory data including markers of myocardium injury were collected one day before and one day after procedure. Data regarding long-term mortality were collected from the Polish National Health Service database.

An experienced team of cardiac surgeons performed the surgeries. Off-pump surgical revascularization is a standard technique for complex coronary artery surgery in the institution. There was no conversion to pump surgery with extracorporeal circulation administration in the presented study group.

\subsection{Outcomes}

The long-term all-cause mortality was the primary outcome in patients with stable multivessel coronary syndrome referred for surgical revascularization in off-pump technique.

\subsection{Statistical Analysis}

In this study, continuous variables were presented as mean \pm standard deviation (SD) or median with interquartile range. Normally distributed data underwent analysis using an unpaired t-test. Not normally distributed data were compared with the use of Mann-Whitney U test. Categorical variables are presented in the study as frequencies and percentages and were compared using a test for proportions. Receiver operating characteristic (ROC) curve were applied for the cut-offs values of the analyzed predictors that discriminated between individuals enrolled in the study with and without mortality endpoint. The long-term mortality predictors estimated in the study was analyzed by the Cox's proportional hazards model. There were univariate and multivariate analyses were performed with adjustment of the estimated coefficients to the coexistence of other predictors. Stepwise, backward selection procedures were applied for the multivariate analysis. The hazard ratios (HR) and their $95 \%$ confidence intervals (CI) were used to show results. The continuous parameters were transformed into binary parameters (using ROC analysis).

\section{Results}

The study group comprised of 682 consecutive patients (131 (19\%) females and 551 (81\%) males) with median age of 66 (60-71) who underwent OPCAB procedures between January 2014 and December 2018 in our hospital. The co-morbidities in the studied population included arterial hypertension in 530 patients $(78 \%)$, diabetes mellitus in $232(34 \%)$, hypercholesterolemia in 396 (58\%), chronic obstructive pulmonary disease (COPD) in 63 (9\%), and chronic kidney disease defined as glomerular filtration rate (GFR) $\leq 60 \mathrm{~mL} / \mathrm{min} / 1.63 \mathrm{~m}^{2}$ according to the Cockcroft-Gault equation in $38(6 \%)$ subjects.

The indication for surgery included: left main stem stenosis in $259(38 \%)$ patients, followed by two vessels disease in 218 (32\%) and three vessels disease in $205(30 \%)$ patients. The mean surgery (skin-to-skin) time was $2.4 \pm 0.4 \mathrm{~h}$, and the mean number of performed anastomoses was $2.3 \pm 0.2$. None of the surgeries were performed as a redo surgery. The re-thoracotomy incidence was 21 (3\%), with median time of ICU stay 25 (17-34) hours. 
There were only 4 cases $(0.5 \%)$ of postoperative stroke and 4 cases $(0.5 \%)$ of respiratory insufficiency.

The 30-day mortality rate included no intraoperative episodes and reached the overall value of $1 \%$ (seven patients). During the median $5.3+/-1.9$ years follow-up, there was a $87 \%$ cumulative survival rate. Table 1 present the clinical characteristics of patients enrolled into the study with division depending on mortality endpoint.

Table 1. Demographical, clinical, and laboratory characteristics of the presented groups.

\begin{tabular}{|c|c|c|c|}
\hline Parameters & $\begin{array}{c}\text { Survivors } \\
\text { No }=598(\%)\end{array}$ & $\begin{array}{c}\text { Deaths } \\
\text { No }=84(\%)\end{array}$ & $p$-Value \\
\hline \multicolumn{4}{|l|}{ Demographical data } \\
\hline 1. Gender $(\mathrm{M} / \mathrm{F})$ & $480(80 \%) / 118(20 \%)$ & $71(84 \%) / 13(16 \%)$ & 0.589 \\
\hline 2. Age (years) & $64(59-70)$ & $67(62-73)$ & 0.021 * \\
\hline \multicolumn{4}{|l|}{ Comorbidities } \\
\hline 1. Arterial hypertension $(n(\%))$ & $459((78 \%)$ & $71(85 \%)$ & 0.109 \\
\hline 2. Diabetes mellitus $(n(\%))$ & $209(35 \%)$ & $31(37 \%)$ & 0.676 \\
\hline 3. Hypercholesterolemia $(n(\%))$ & $353(59 \%)$ & $43(51 \%)$ & 0.173 \\
\hline 4. $\operatorname{COPD}(n(\%))$ & $45(8 \%)$ & $18(21 \%)$ & $<0.001$ * \\
\hline 5. $\operatorname{PAD}(n(\%))$ & $84(14 \%)$ & $18(21 \%)$ & $<0.001 *$ \\
\hline 6. kidney failure $(n(\%))$ & $33(6 \%)$ & $5(6 \%)$ & 0.768 \\
\hline \multicolumn{4}{|l|}{ Echocardiography: } \\
\hline 1. preoperative LV diameter (\%) & $48(44-52)$ & $50(45-54)$ & $0.006^{*}$ \\
\hline 2. preoperative LVEF (\%) & $55(50-60)$ & $50(45-60)$ & $<0.001 *$ \\
\hline \multicolumn{4}{|l|}{ Preoperative laboratory tests: } \\
\hline 1. $\mathrm{WBC} \times 10^{9} / \mathrm{L}($ median $(\mathrm{Q} 1-\mathrm{Q} 3))$ & $7.7(6.5-9.1)$ & $7.9(6.8-9.2)$ & 0.657 \\
\hline $\begin{array}{l}\text { 2. Lymphocytes } \times 10^{9} / \mathrm{L} \text { (median } \\
(\mathrm{Q} 1-\mathrm{Q} 3))\end{array}$ & $1.8(1.4-2.3)$ & $1.8(1.4-2.0)$ & 0.196 \\
\hline $\begin{array}{l}\text { 3. Neutrophils } \times 10^{9} / \mathrm{L} \text { (median } \\
(\mathrm{Q} 1-\mathrm{Q} 3))\end{array}$ & $4.9(4-6.2)$ & $5.2(4.2-6.4)$ & 0.165 \\
\hline 3. NLR (median (Q1-Q3)) & $2.7(2-3.7)$ & $2.9(2.3-4.0)$ & $0.039 *$ \\
\hline 4. $\mathrm{Hb} \times 10^{9} / \mathrm{L}($ median $(\mathrm{Q} 1-\mathrm{Q} 3))$ & $8.8(8.2-9.3)$ & $8.6(7.9-9.2)$ & 0.266 \\
\hline $\begin{array}{l}\text { 5. Platelets } \times 10^{3} / \mathrm{uL}(\text { median } \\
(\mathrm{Q} 1-\mathrm{Q} 3))\end{array}$ & $221(189-266)$ & $228(192-268)$ & 0.559 \\
\hline $\begin{array}{l}\text { 6. Monocytes } \times 10^{9} / \mathrm{L}(\text { median } \\
(\mathrm{Q} 1-\mathrm{Q} 3))\end{array}$ & $0.5(0.4-0.6)$ & $0.5(0.4-0.6)$ & $0.022 *$ \\
\hline 7. MLR (median (Q1-Q3)) & $0.3(0.2-0.3)$ & $0.3(0.2-0.3)$ & $<0.001 *$ \\
\hline $\begin{array}{l}\text { 8. } \mathrm{MCHC}(\mathrm{mmol} / \mathrm{dL}) \text { (median } \\
\text { (Q1-Q3)) }\end{array}$ & $21.2(20.7-21.6)$ & $20.9(20.5-21.3)$ & 0.378 \\
\hline 9. PLR (mean +/-SD) & $134+/-63$ & $148+/-79$ & 0.105 \\
\hline
\end{tabular}

COPD—chronic obstructive pulmonary disease, $\mathrm{Hb}$-hemoglobin, LV—left ventricle, LVEF-left ventricle ejection fraction, $\mathrm{MCHC}$ - mean corpuscular hemoglobin concentration, MLR-monocyte to lymphocyte ratio, NLRneutrophil to lymphocyte ratio, No-number, PAD—peripheral artery disease, PLR_platelets to lymphocyte ratio, SD—standard deviation, WBC—white blood cells. * - statistically significant difference.

Mann-Whitney tests revealed significant differences between the presented groups, including age $(p=0.021)$, concomitant diseases including chronic obstructive pulmonary disease $(p<0.001)$, peripheral artery disease (PAD) $(p<0.001)$, and results from laboratory tests including neutrophil to lymphocyte ratio (NLR) $(p=0.039)$, monocytes $(p=0.022)$, and monocyte to lymphocyte ratio (MLR) $(p<0.001)$.

Postoperative characteristics analysis (Table 2 ) showed significant differences in MannWhitney tests including laboratory tests-lymphocytes $(p=0.018)$, neutrophils $(p=0.003)$, NLR $(p<0.001), \operatorname{MLR}(p=0.023)$, mean corpuscular hemoglobin concentration (MCHC) $(p=0.006)$. Among echocardiographic features, left ventricle diastolic diameter $(p<0.001)$ and postoperative left ventricle ejection fraction $(p<0.0001)$ were significantly differed.

We performed whole group analysis to estimate cut-off values for long-term survival rates. The factors influencing long-term mortality rate included age over $62(p=0.009)$, COPD $(p<0.001)$, peripheral artery disease $(p<0.001)$. Among echocardiographic parameters, preoperative left ventricle ejection fraction below $50 \%(p<0.001)$ and postoperative 
LVEF values below $45 \%(p<0.001)$ were significantly related to increased mortality rates. Among hematological indices, preoperative NLR above $2.5(p=0.019)$ and postoperative NLR values above $3.5(p<0.0001)$ were related to long-term prognosis, respectively. MLR values above $0.2(p=0.006)$ and $0.49(p=0.009)$ in preoperative and postoperative results were also related to long-term prognosis, respectively. There were two more simple parameters found to be statistically significant for long-term results, including MCHC above 21.2 $(p<0.001)$ and PLR above $136(p=0.039)$, as presented in Table 3.

Table 2. Postoperative characteristics.

\begin{tabular}{|c|c|c|c|}
\hline Parameters & $\begin{array}{l}\text { Survivors } \\
\text { No }=598\end{array}$ & $\begin{array}{c}\text { Deaths } \\
\text { No }=83\end{array}$ & $p$-Value \\
\hline \multicolumn{4}{|l|}{ Surgical characteristics: } \\
\hline 1.number of grafts $(n)($ mean/SD) & $2.3+/-0.2$ & $2.3+/-0.2$ & 0.843 \\
\hline 2. skin-to-skin time (h) (mean/SD) & $2.4+/-0.4$ & $2.4+/-0.3$ & 0.782 \\
\hline \multicolumn{4}{|l|}{ Laboratory test results: } \\
\hline 1. WBC $\times 10^{9} / \mathrm{L}($ median $(\mathrm{Q} 1-\mathrm{Q} 3))$ & $8.4(6.9-10.2)$ & $8.8(7.4-10.7)$ & 0.118 \\
\hline 2. Lymphocytes $\times 10^{9} / \mathrm{L}($ median $(\mathrm{Q} 1-\mathrm{Q} 3))$ & $1.9(1.5-2.5)$ & $1.8(1.3-2.2)$ & $0018 *$ \\
\hline 3. Neutrophils $\times 10^{9} / \mathrm{L}($ median $(\mathrm{Q} 1-\mathrm{Q} 3))$ & $5(3.7-6.4)$ & $5(3.7-6.4)$ & $0.003 *$ \\
\hline 3. NLR (median (Q1-Q3)) & $2.6(1.8-3.5)$ & $5.6(4.5-7.2)$ & $<0.001$ * \\
\hline 4. $\mathrm{Hb}(\mathrm{mmol} / \mathrm{dL})$ (median (Q1-Q3)) & $6.9(6.5-7.3)$ & $6.9(6.5-7.3)$ & 0.609 \\
\hline 5. Platelets $\times 10^{3} / \mathrm{uL}($ median $(\mathrm{Q} 1-\mathrm{Q} 3))$ & $278(230-343)$ & $290(221-382)$ & 0.457 \\
\hline 6. Monocytes $\times 10^{9} / \mathrm{L}($ median $(\mathrm{Q} 1-\mathrm{Q} 3))$ & $0.9(0.7-1.1)$ & $0.9(0.7-1.2)$ & 0.696 \\
\hline 7. MLR (median (Q1-Q3)) & $0.5(0.3-0.6)$ & $0.5(0.4-0.7)$ & $0.023 *$ \\
\hline 8. $\mathrm{MCHC}(\mathrm{mmol} / \mathrm{dL})($ median $(\mathrm{Q} 1-\mathrm{Q} 3))$ & $21.3(20.8-21.7)$ & $21.1(20.7-21.6)$ & 0.006 * \\
\hline 9. PLR (mean + / - SD) & $134+/-63$ & $186+/-96$ & 0.869 \\
\hline 10. Troponin-I (median (Q1-Q3)) & $1.6(0.8-3.8)$ & $1.8(0.6-5.4)$ & 0.578 \\
\hline \multicolumn{4}{|l|}{ Echocardiography: } \\
\hline 1. LV diameter (mm) (median (Q1-Q3)) & $47(44-51)$ & $50(46-55)$ & $<0.001$ * \\
\hline 2. postoperative LVEF (\%) (median (Q1-Q3)) & $60(50-60)$ & $45(40-55)$ & $<0.001$ * \\
\hline $\begin{array}{l}\text { Overall duration of hospitalization (days) } \\
\text { (median (Q1-Q3)) }\end{array}$ & $12(7-13)$ & $128-13)$ & $p=0.783$ \\
\hline
\end{tabular}

Abbreviations: $\mathrm{Hb} —$ hemoglobin, $\mathrm{LV}$-left ventricle, LVEF—left ventricle ejection fraction, MCHC—mean corpuscular hemoglobin concentration, MLR-monocyte to lymphocyte ratio, NLR-neutrophil to lymphocyte ratio, PLR - platelets to lymphocyte ratio, SD—standard deviation, WBC—white blood cells, No-number. *-statistically significant difference.

Table 3. Parameters related to long-term prognosis following OPCAB procedure.

\begin{tabular}{cccccc}
\hline Parameter & $\begin{array}{c}\text { Cut-off } \\
\text { Point }\end{array}$ & AUC & $\begin{array}{c}\text { Sensitivity } \\
\mathbf{( \% )}\end{array}$ & $\begin{array}{c}\text { Specificity } \\
\mathbf{( \% )}\end{array}$ & $p$-Value \\
\hline $\begin{array}{c}\text { Demographical: } \\
\text { 1. Age }\end{array}$ & $>62$ years & 0.578 & 73.81 & 41.14 & $p=0.019$ \\
Echocardiography: & & & & & \\
1. Preoperative LV & LV $>49 \mathrm{~mm}$ & 0.594 & 51.81 & 63.16 & $<0.005$ \\
2. Preoperative LVEF & LVEF $<50 \%$ & 0.639 & 61.45 & 60.27 & $<0.001$ \\
3. Postoperative LV & LV $>48 \mathrm{~mm}$ & 0.633 & 67.47 & 58.74 & $<0.001$ \\
4. Postoperative LVEF & LVEF $<45 \%$ & 0.718 & 53.01 & 83.02 & $<0.001$ \\
Haematological indices: & & & & & \\
1. Preoperative NLR & NLR $>2.5$ & 0.570 & 68.67 & 45.52 & 0.025 \\
2. Postoperative NLR & NLR $>3.5$ & 0.640 & 49.40 & 75.80 & $<0.001$ \\
3. Preoperative MLR & MLR $>0.2$ & 0.577 & 84.34 & 32.49 & 0.012 \\
4. Postoperative MLR & MLR $>0.49$ & 0.577 & 84.34 & 57.19 & 0.025 \\
5. Preoperative MCHC & MCHC $<21.1$ & 0.613 & 59.04 & 56.80 & $<0.001$ \\
6. Postoperative MCHC & MCHC $<21.2$ & 0.581 & 65.48 & 60.10 & 0.016 \\
7. Postoperative PLR & PLR $>136$ & 0.593 & 55.95 & 57.79 & 0.039 \\
\hline Abbreviations: AUC-area under the curve COPD—chronic obstructive pulmonary disease, LVEF-left ventricle
\end{tabular}

Abbreviations: AUC - area under the curve, COPD—chronic obstructive pulmonary disease, LVEF-left ventricle ejection fraction, $\mathrm{MCHC}$-mean corpuscular hemoglobin concentration, MLR — monocyte to lymphocyte ratio, NLR - neutrophil to lymphocyte ratio, PAD—peripheral artery disease, PLR - platelets to lymphocyte ratio. 


\subsection{Univariable Analysis}

In univariate analysis, age above 62 years $(\mathrm{HR}=1.97,95 \%$ CI 1.19-3.24, $p=0.006)$ and comorbidities including COPD (HR $=2.77,95 \%$ CI 1.64-4.68, $p=0.000)$ and PAD $(\mathrm{HR}=2.36,95 \%$ CI 1.47-3.79, $p=0.000)$ were statistically significant. Preoperative laboratory parameters presenting significant relation to long-term prognosis included NLR $>2.5$ $(\mathrm{HR}=1.75,95 \%$ CI 1.09-2.79, $p=0.019), \mathrm{MLR}>0.2(\mathrm{HR}=2.46,95 \%$ CI 1.33-4.55, $p=0.004)$, and PLR $(\mathrm{HR}=1.01,95 \%$ CI 1.00-1.01, $p=0.039)$. Postoperative laboratory parameters presenting significant relation included NLR $>3.5(\mathrm{HR}=2.66,95 \%$ CI $1.72-4.12, p=0.000)$, MLR > $0.5(\mathrm{HR}=1.78,95 \%$ CI $1.13-2.78, p=0.012)$ and PLR $>136(\mathrm{HR}=2.18,95 \% \mathrm{CI}$ $1.31-3.62, p=0.003)$. Table 4 presents the Cox univariable regression model performed to determine parameters that were calculated as a significant predictors of mortality after off-pump surgical revascularization.

Table 4. Cox regression univariable analysis.

\begin{tabular}{|c|c|c|c|}
\hline Parameter & HR & $95 \% \mathrm{CI}$ & $p$-Value \\
\hline \multicolumn{4}{|l|}{ Demographical and clinical: } \\
\hline 1. Age & 1.04 & $1.01-1.07$ & 0.006 \\
\hline 2. Age $>62$ years & 1.97 & $1.19-3.24$ & 0.007 \\
\hline 3. COPD & 2.77 & $1.64-4.68$ & $<0.001$ \\
\hline 4.PAD & 2.36 & $1.47-3.79$ & $<0.001$ \\
\hline \multicolumn{4}{|l|}{ Preoperative parameters: } \\
\hline 1. WBC & 1 & $0.93-1.07$ & 0.984 \\
\hline 2. NLR $>2.5$ & 1.75 & $1.09-2.79$ & 0.019 \\
\hline 3. MLR > 0.2 & 2.46 & $1.33-4.55$ & 0.004 \\
\hline 4. $\mathrm{MCHC}$ & 0.67 & $0.47-0.94$ & 0.021 \\
\hline 5. $\mathrm{MCHC}>21.1$ & & $1.05-2.65$ & 0.028 \\
\hline 6. PLR & 1.01 & $1.00-1.01$ & 0.039 \\
\hline \multicolumn{4}{|l|}{ Postoperative parameters: } \\
\hline 1. WBC & 1.05 & $1.02-1.08$ & 0.004 \\
\hline 2. Lymphocytes & 0.67 & $0.47-0.94$ & 0.02 \\
\hline 3. Lymphocytes $<2.6$ & 2.34 & $1.08-5.08$ & 0.032 \\
\hline 4. Neutrophils & 1.12 & $1.07-1.16$ & $<0.001$ \\
\hline 5. Neutrophils $>5.3$ & 1.92 & $1.23-3.00$ & 0.004 \\
\hline 6. NLR & 1.16 & $1.10-1.22$ & $<0.001$ \\
\hline 7. $\mathrm{NLR}>3.5$ & 2.66 & $1.72-4.12$ & $<0.001$ \\
\hline 8. MLR > 0.49 & 1.78 & $1.13-2.78$ & 0.012 \\
\hline 9. PLR & 1 & $1.00-1.01$ & 0.005 \\
\hline 10. PLR > 136 & 2.18 & $1.31-3.62$ & 0.003 \\
\hline \multicolumn{4}{|l|}{ Echocardiography: } \\
\hline 1. Preoperative LV & 1.04 & $1.01-1.07$ & 0.21 \\
\hline 2. Preoperative LV > $49 \mathrm{~mm}$ & 1.53 & $0.98-2.38$ & 0.058 \\
\hline 3. Preoperative LVEF & 0.96 & $0.94-0.98$ & $<0.001$ \\
\hline 4. $\mathrm{LVEF}<50 \%$ & 2.31 & $1.47-3.61$ & $<0.001$ \\
\hline 5. Postoperative LV & 1.06 & $1.03-1.09$ & $<0.001$ \\
\hline 6. Postoperative LV $>48 \mathrm{~mm}$ & 2.41 & $1.50-3.87$ & $<0.001$ \\
\hline 7. Postoperative LVEF & 0.94 & $0.93-0.96$ & $<0.001$ \\
\hline 8. Postoperative LVEF $<45 \%$ & 3.49 & $2.21-5.52$ & $<0.001$ \\
\hline
\end{tabular}

Abbreviations: COPD—chronic obstructive pulmonary disease, $\mathrm{Hb}$-hemoglobin, $\mathrm{LV}$-left ventricle, LVEF—left ventricle ejection fraction, $\mathrm{MCHC}$ - mean corpuscular hemoglobin concentration, MLR-monocyte to lymphocyte ratio, NLR — neutrophil to lymphocyte ratio, PAD—peripheral artery disease, PLR - platelets to lymphocyte ratio, WBC-white blood cells.

\subsection{Multivariable Analysis}

Parameters significant in univariable analysis were subsequently verified in a multivariate analysis. Table 3 presents the Cox multivariable regression model for significant mortality predictors after surgical revascularization in off-pump technique. Age over 62 and COPD were significant clinical factors in a multivariable analysis. The laboratory parameters including preoperative MLR > 0.2 (HR 2.46, 95\% CI 1.33-4.55, $p=0.004)$ and 
postoperative NLR > 3.5 (HR 1.75, 95\% CI 1.09-2.79, $p=0.019)$ were found significant for long-term mortality prediction in multivariable analysis. Predictive echocardiographic parameters including pre- and post-operative LV diameters and LVEF are shown in Table 5.

Table 5. Multivariable analysis.

\begin{tabular}{lccc}
\hline Parameter & HR & $\mathbf{9 5 \%}$ CI & $p$-Value \\
\hline Demographical and clinical: & & & \\
1. Age above 62 years & 1.75 & $1.05-2.91$ & 0.03 \\
2. COPD & 3.01 & $1.74-5.24$ & 0 \\
Laboratory parameters: & & & \\
1. Postoperative WBC & 1.05 & $0.93-1.07$ & 0.984 \\
2. Postoperative NLR > 3.5 & 1.75 & $1.09-2.79$ & 0.018 \\
3. Preoperative MLR > 0.2 & 1.98 & $1.05-3.68$ & 0.034 \\
$\quad$ Echocardiography: & & & \\
1. Preoperative LV > 49 mm & 0.46 & $0.24-0.85$ & 0.014 \\
2. Postoperative LV > 48 mm & 2.53 & $1.29-4.95$ & 0.007 \\
3. Postoperative LVEF & 0.95 & $0.93-0.97$ & 0 \\
\hline COPD—chronic obstructive pulmonary disease, LV-left ventricle, LVEF-left ventricle ejection fraction, MCHC-
\end{tabular}

COPD—chronic obstructive pulmonary disease, LV—left ventricle, LVEF—left ventricle ejection fraction, MCHCmean corpuscular hemoglobin concentration, MLR—-monocyte to lymphocyte ratio, NLR—-neutrophil to lymphocyte ratio, WBC-white blood cells.

\subsection{Receiver Operator Characteristics (ROC) Analysis}

Receiver operator characteristics revealed age over 62 as a long-term mortality factor (AUC $=0.578, p=0.019)$ yielding sensitivity of $73.18 \%$ and specificity of $41.14 \%$.

\subsubsection{Preoperative NLR, MLR, and PLR}

Among preoperative laboratory tests, the ROC analysis has shown that the optimal cut-off points for predicting long-term mortality after OPCAB procedure based on preoperative NLR $>2.5$ (AUC $=0.057, p=0.025$ ) with highest sensitivity of $68.67 \%$ and specificity of $45.52 \%$, as presented in Figure 1a. Similar, the ROC analysis selected the NLR $>2.5$ (AUC $=0.0577, p=0.012$ ) yielding sensitivity of $84.34 \%$ and specificity of $32.49 \%$, as presented in Figure 1b.

(a)

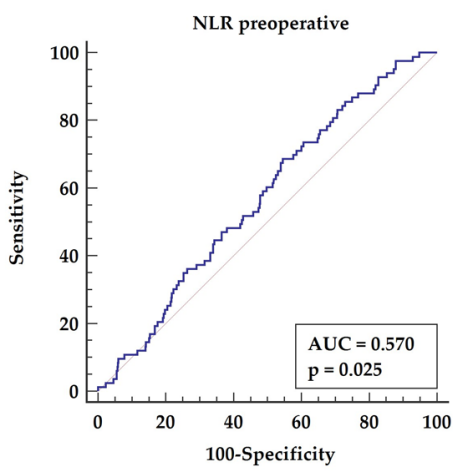

(b)

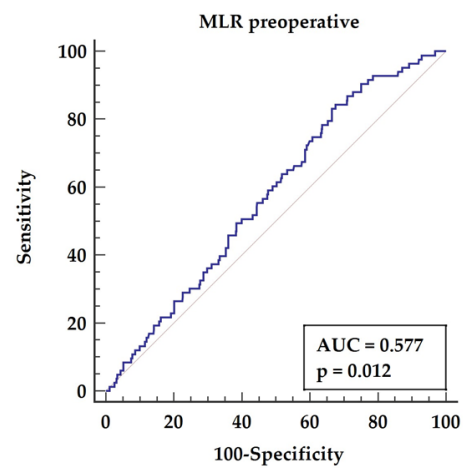

(c)

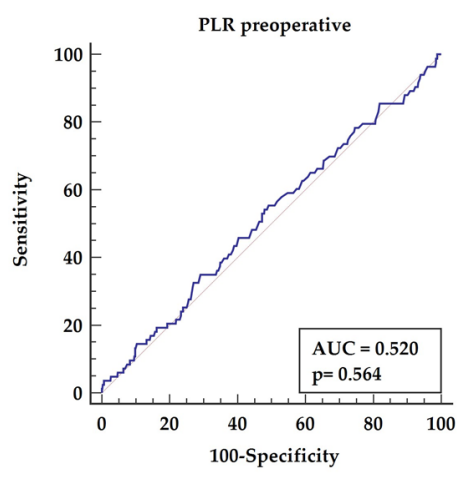

Figure 1. Receiver characteristics operator for long-term mortality basing on preoperative indices (NLR, MLR and PLR (a-c)). Abbreviations: AUC-area under the curve, M/Lmonocyte/Lymphocyte, N/L—neutrophil/lymphocyte, P/L—platelets/lymphocyte.

The ROC analysis has shown that there was no significant relation between preoperative PLR and long-term mortality rate. The cut-off points estimated by ROC analysis was for PLR above 128 (AUC $=0.555, p=0.09$ ) with sensitivity of $57.83 \%$ and specificity of $54.56 \%$, as presented in Figure 1c. 


\subsubsection{Postoperative NLR, MLR, and PLR}

Based on a postoperative laboratory test, the ROC analysis showed that the optimal cut-off point for predicting long-term mortality after an OPCAB procedure for NLR $>3.5$ (AUC $=0.640, p<0.0001$ ) yielding sensitivity of $49.40 \%$ and specificity of $75.80 \%$, as presented in Figure 2a.

(a)

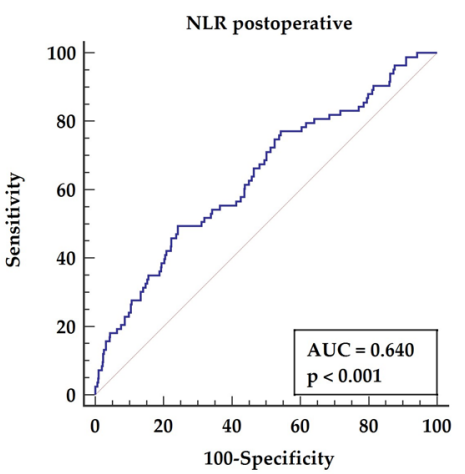

(b)

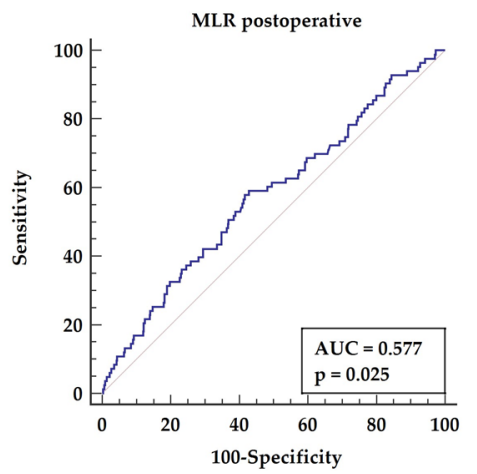

(c)

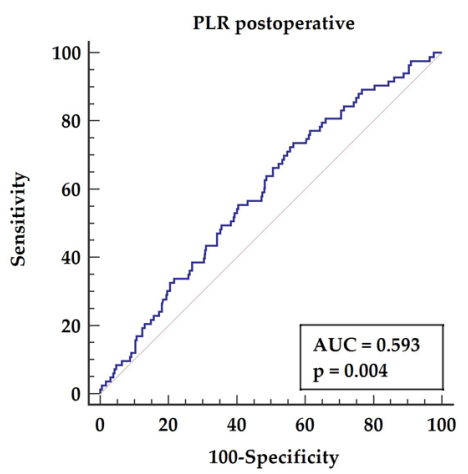

Figure 2. Receiver characteristics operator for long-term mortality basing on postoperative indices (NLR, MLR and PLR (a-c)). Abbreviations: AUC-area under the curve, M/Lmonocyte/lymphocyte, N/L—neutrophil/lymphocyte, P/L—platelets/lymphocyte.

The ROC analysis has shown that the optimal cut-off points for predicting long-term mortality after an OPCAB procedure based on MLR $>0.49$ (AUC $=0.577, p=0.025)$, giving sensitivity of $59.04 \%$ and specificity of $57.19 \%$, as presented in Figure $2 \mathrm{~b}$. The ROC analysis has shown that the optimal cut-off points for predicting long-term mortality after the OPCAB procedure basing on PLR $>136$ (AUC $=0.593, p=0.004$ ), giving sensitivity of $53.01 \%$ and specificity of $83.02 \%$, as presented in Figure 2c.

Basing on a postoperative laboratory test, the ROC analysis has shown that the optimal cut-off point for predicting long-term mortality after the OPCAB procedure for NLR $>3.5$ (AUC $=0.640, p<0.0001$ ), yielding sensitivity of $49.40 \%$ and specificity of $75.80 \%$, as presented in Figure 2a.

The cut-off points for MLR and PLR of $>0.49$ (AUC $=0.577, p=0.025$ ) and $>136$ (AUC $=0.593, p=0.004$ ) were found, with sensitivity of $59.04 \%$ and specificity $57.19 \%$, and sensitivity $53.01 \%$ and specificity $83.02 \%$, respectively (Figure $2 b, c$ ).

Single inflammatory parameters represented a moderate predictive value in receiver characteristic operator analysis. Therefore, we constructed a multivariable model based on demographical and clinical parameters combined with inflammatory markers.

Multifactorial models were constructed separately for preoperative and postoperative parameters.

The preoperative multifactorial model was based on the following parameters: age above 62 years $(p=0.0238)$, left ventricle ejection fraction below $50 \%(p<0.0001)$, MLR above $0.2(p=0.0186)$, MCHC below $21.1(p=0.008)$. ROC analysis for the constructed model is characterized by AUC $=0.699(p<0.001)$, yielding sensitivity of $65.06 \%$ and specificity of $67.18 \%$, as presented in Figure 3 .

The separate postoperative multifactorial model was composed of the following parameters: age above 62 years $(p=0.0177)$, left ventricle ejection fraction below $45 \%$ $(p<0.0001)$, left ventricle diameter above $48 \mathrm{~mm}(p=0.0125)$, and NLR above $3.5(p=0.0003)$. The ROC analysis for the constructed postoperative model is characterized by (AUC $=0.747$, $p<0.001$ ), giving sensitivity of $77.11 \%$ and specificity of $59.83 \%$, as presented in Figure 4 . 


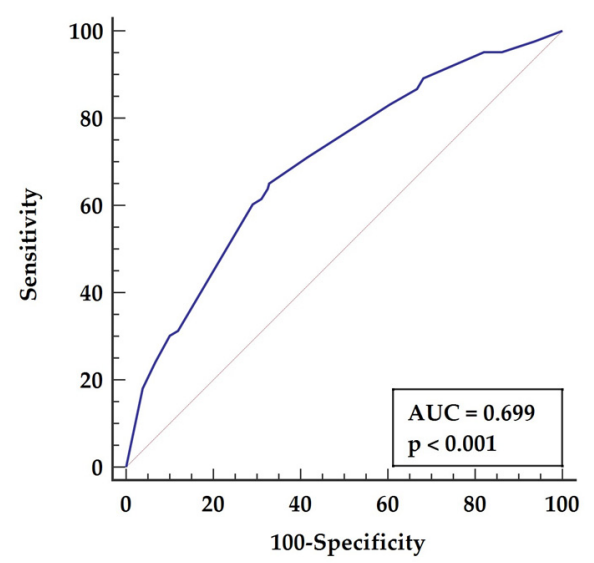

Figure 3. Receiver characteristics operator for long-term mortality basing on a preoperative multifactoral model. Abbreviations: AUC—area under the curve.

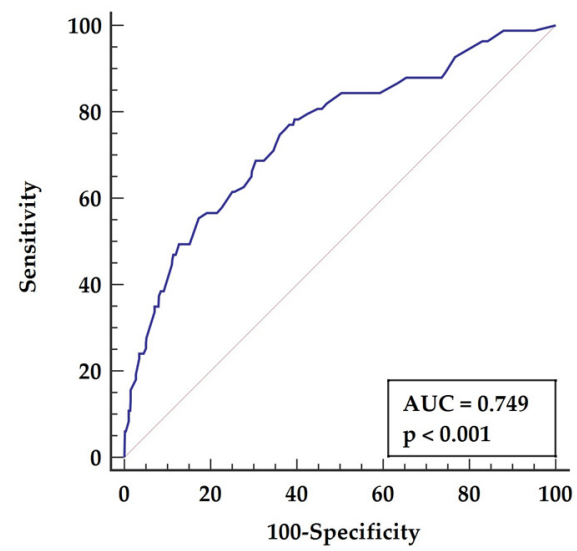

Figure 4. Receiver characteristics operator for long-term mortality based on postoperative multifactoral model. Abbreviations: AUC-area under the curve.

\section{Discussion}

We have presented a detailed analysis of clinical factors and hematological indices that have prognostic value for long-term mortality prediction. The major finding of our study is the significant relation between simple inflammatory markers, such as MLR, NLR, and PLR in OPCAB patients and their mortality risk. Moreover, we also constructed separate two multifactorial models for mortality prediction composed from preoperative and postoperative parameters. The inflammatory markers, in combination with demographical (age) and echocardiographic results (including left ventricle diameter and left ventricle ejection fraction), occurred as significant predictors of long-term results in off-pump surgery. We have focused on preoperative values of indices and their results obtained in early inflammatory phase after the off-pump procedure. The multivariable analysis revealed a relation between preoperative MLR above 0.2 and postoperative NLR 3.5 as predictive factors. The cut-off point for patients' age was estimated at 62 years regarding long-term mortality. The echocardiographic parameters representing significant predictive factors included left ventricle diameter and left ventricles ejection fraction.

Several possible mechanisms may explain the relationship between inflammatory indices and cardiovascular risk. Chronic exposure to metabolic risk factors, including hyperlipidemia, hyperglycemias, and smoking, causes endothelial disfunction, further accompanied by inflammatory response [36]. Inflammation causes vascular damage elicited by immune cells [37]. The major harm cells are neutrophils, which are specified to innate immunity-limiting pathogen dissemination and further activating adaptive immunity [38]. When activated in inflammation, neutrophils generate highly reactive oxygen species, which generally contribute to pathogen inactivation and death, but also have a deleterious 
effect on the vascular wall [37]. Moreover, neutrophils form extracellular traps (NETs) that help to destroy pathogens but may also promote thrombosis and coagulation [38]. After damage to the endothelium, neutrophils are recruited even before platelets and promote platelet activation and deposition [39]. Activated platelets in turn facilitate the recruitment of inflammatory cells to the atherosclerotic lesion and release plenty of mediators, thus enriching the inflammatory milieu [40]. Several other neutrophils' mediators are also released, recruiting other leucocytes, or disrupting the endothelial cell structure [37]. Neutrophils also play a sufficient role in later stages of atherosclerotic lesion formation, aggravating and sustaining the chronic inflammatory setting and recruitment of circulating monocytes [41]. Monocytes are pro-inflammatory cells of innate immunity, producing cytokines, chemokines, and reactive oxidative species [42]. After recruitment, monocytes in turn take up oxidized lipids and form foam cells, which constitute the atherosclerotic plaque core in arterial wall $[37,43]$. Consecutively, monocytes' secretion of proinflammatory cytokines (interleukin-1, TNF-alfa), enzymes (myeloperoxidase, matrix metalloproteinases), and growth factors occurs and leads to formation of atherogenic dysfunctional lipoproteins, facilitation of plaque destabilization, and development of atherothrombotic complications [36,42]. Contribution of monocytes in atherosclerosis also comprises of angiogenesis and tissue repair [42]. Progressing plaques may rupture, causing acute ischemic events and clinically unstable angina, myocardial infarction, or stroke. Endothelial wall rupture triggers activation of platelets, which leads to several processes included in thrombus formation. In patients with coronary artery disease, antiplatelet therapy is crucial in the prevention and treatment of both its stable and unstable stages.

Conversely, lymphocytes may play protective or pro-atherogenic roles, depending on the cell subset, either T-cells or B-cells or natural killer T (NK T) cells [44]. The number of B-cells is low, and T-cells high in atherosclerotic plaque [45]. In brief, Th1 cells secrete INF- $\gamma$, promote endothelial dysfunction and lipid accumulation in macrophages, thus exerting a pro-atherogenic effect, and regulatory $\mathrm{T}$ cells induce tolerance, inhibition of atherogenic T subsets, and suppression of inflammation [44,46]. The role of Th2 is more complex as both pro- and anti-atherogenic actions have been described [46]. B-cells produce antibodies, which may exert a protective action by inhibiting the uptake of oxidized lipids by macrophages and by favouring the clearance of apoptotic bodies, or may enhance the uptake of cholesterol favouring atherosclerosis, depending on the antibody type [44]. Therefore, the role of lymphocytes, though believed as atheroprotective, is complex. A low lymphocyte count was described to be linked to inferior cardiovascular outcomes in individuals with coronary artery disease and congestive failure of the heart [47].

This brief summary of the pro- or anti-atherogenic effects of different blood cells and particles points out the purpose of NLR, MLR, and PLR use in the assessment of coronary artery disease. We proved its significance in prediction of long-term survival after OPCAB. The whole blood analysis is a simple and routine test but may provide crucial prognostic information for practitioners. Patients who present with abnormally increased values of pre-operative and post-operative NLR, MLR, and PLR should undergo meticulous follow-up controls, as they are burdened with a higher risk of death.

\subsection{Neutrophil to Lymphocyte Ratio (NLR)}

Neutrophil to lymphocyte ratio is considered a useful inflammatory marker. Increased preoperative values of NLR were presented by Weedle et al. [48] to be associated with postoperative atrial fibrillation in cardiac surgery. Patients who develop atrial fibrillation after heart surgery experience acute oxidative stress as a complication related to inflammatory reaction following surgery [49]. Giakoumidakis et al. in their study found a relationship between perioperative NLR and higher mortality, both in-hospital and 30-day, and prolonged postoperative hospitalization [50]. Another relatively common complication, considered an autoimmune phenomenon, is post-pericardiotomy syndrome (PPS). Sevuk at al. in their study presented the predictive value of NLR with cut-off point of 8.34 for PPS risk. The overall mortality risk after cardiac surgery and its relation to NLR was postulated by Green 
at al. [51]. Their results were based on preoperative values including temporal stability of the presented ratio. We investigated preoperative NLR to predict risk for long-term survival, including preoperative and perioperative values. Afterwards we focused on perioperative changes of the aforementioned ratio as a possible marker of inflammatory reactivity secondary to surgical injury. Closer follow-up of patients undergoing surgical procedures based on perioperative NLR was postulated by Bath et al. [52]. NLR increase in early inflammatory phase after cardiac surgery procedures with concomitant activation of CD16 mean fluorescence index (MFI) (non-classical monocytes) was postulated in a previous report supporting the use of NLR as an inflammatory marker for outcomes prediction [53]. Preoperative NLR values above 3.36 were found significant for mortality prediction in a 30-day analysis by Haran et al. [54]. The relationship between preoperative values of NLR above 2.6 and long-term survival after heart surgery was presented by Silberman et al. [55]. Studies present a relationship between NLR and cardiac surgery procedures performed with cardiopulmonary bypass application. Utility of extracorporeal circulation indicate systemic inflammatory response (SIRS) [56,57]. Aldemir et al., in their report, presented significant NLR differences in the early inflammatory phase following surgical revascularization performed off-pump and on-pump [58]. The next reports presented by our group pointed out the relation between NLR results obtained in the early postoperative phase and long-term results in OPCAB patients $[59,60]$. NLR was investigated in acute postoperative kidney dysfunction after surgical revascularization and pointed out as a significant preoperative factor by Parlar et al. [61]. Interestingly, the preoperative NLR and risk for venous grafts occlusion was also inversely correlated [62]. The relation between elevated NLR and worse venous grafts patency rate can be explained by endothelial shear stress activation of pro-inflammatory signalling pathways [63]. Sterpetti et al. in vitro and in vivo models showed the differences in interleukins and TNF- alfa release by venous grafts' endothelial cells in relation to hemodynamic stress. We present the results of early reperfusion, suggesting that overactivity of the inflammatory system following off-pump procedures can predispose patients for graft endothelium injury as proinflammatory cytokines are released. The role of immunomodulation in vein graft failure in humans was reviewed by Baganha et al. [64]. Immune cells in long-term intimal hyperplasia and accelerated atherosclerosis were presented on experimental and clinical basis. This is one of the possible explanations of pathophysiology of vein graft occlusion as better understanding of the processes taking place in endothelium would give a chance for better failure prevention [65]. We hypothesize that graft failure prevention should be focused on factors similar to those linked to cardiac graft vasculopathy. The relation between immune and non-immune agents are underlined including reperfusion injury, coronary endothelial dysfunction, and inflammation [66]. The meta-analysis performed by Jackson et al. on patients referred for vascular procedures link the preoperative NLR to all-cause mortality and indicate the relation between immune and non-immune individual predisposition to over reactivity of the inflammatory system [67]. The results from our study, presenting increased postoperative NLR (above 3.5) as a significant mortality factor in multivariable analysis, is a compromise with previous reports.

\subsection{Monocytes to Lymphocyte Ratio (MLR)}

The incidence of diseases with an inflammatory etiopathology has augmented, especially in societies with high socioeconomic status [68] development. The genesis of atherosclerosis-related diseases is believed to be related to reprogramming of the innate immune system as a result of activation and recruitment of monocyte-derived macrophages [69]. The activation of endothelium induces monocytes arrest onto the vessel wall. They transmigrate into the arterial wall and mature into macrophages [70]. In animal models, monocytes enter into the atherosclerotic plaques more readily if hypercholesterolemia co-exists [71]. MLR was shown to be an independent risk factor for the severity of cardiovascular diseases [72]. The atherosclerotic plaque development begins at sites of disturbed flow and subsequent macrophage accumulation [73]. The MLR was evaluated in propensity 
score analysis regarding four-year mortality risk following surgical revascularization with cardiopulmonary bypass application (on-pump technique) and was presented by Zhou et al. [74]. The results of our study revealed in a multivariable analysis that preoperative MLR > 0.2 was regarded as a significant factor for long-term mortality following off-pump revascularization. Preoperative MLR in multiple logistic regression analyses by Oksuz et al. were shown to be an independent predictor of venous graft failure [75]. In a retrospective observational study by Cai et al. performed on STEMI patients undergoing percutaneous procedures, MLR was related to worse overall prognosis [76].

\subsection{Platelets to Lymphocyte Ratio (PLR)}

PLR reflects the relationship between prothrombotic and inflammatory state. This ratio was first used in oncological studies as a marker of worse prognosis [77]. Subsequently it gathered growing interest in patients with coronary artery disease since both platelets and lymphocytes, as mentioned above, are included in inflammatory reaction. Elevated platelet count is by itself associated with worse cardiovascular outcomes [78,79] and high on-treatment platelet reactivity and resistance to antiplatelet therapy [80]. This may result from more advanced inflammatory response. In turn, a low lymphocyte count is associated with a higher risk of subsequent cardiac events after episodes of unstable angina [81]. Therefore, joint platelet and lymphocyte count should logically reflect both pathways of inflammation exaggeration and thrombosis burden in atherosclerosis. Indeed, PLR was evaluated in several studies. Yüksel et al. [82] showed that high PLR level is associated with the severity of coronary atheromatic changes. The pre-procedural PLR $>111$ predicted severe atherosclerosis with sensitivity of $61 \%$ and specificity of $59 \%$. Several subsequent studies confirmed a similar result $[83,84]$. A high level of PLR was also observed in instable angina with chronic total occlusion and poorly developed coronary collateral circulation, independent from platelet or lymphocyte count alone [85]. Azab et al. [86] found PLR to be an independent significant predictor of long-term mortality after non-ST elevation myocardial infarction. That finding was not solely related to lymphocytopenia as it was also true for patients with normal lymphocyte count. PLR $>176$ was a significant predictor of four-year all-cause mortality after exclusion of 30-day deaths. The authors concluded that elevated PLR may be treated as a predictor of long-term mortality rather than a marker of acute syndrome. In patients with STEMI treated with coronary angioplasty, PLR was a no-reflow phenomenon predictor [87] and long-term mortality [88]. The usage of PLR, obtained before angioplasty, for adverse events and long-term mortality prediction, has been reported [89-92]. Qiu et al. [85] performed a meta-analysis of 14 studies presenting an association between PLR and chronic coronary syndrome. On the basis of current evidence, the authors pointed out the usefulness of PLR for predicting severe stenosis, collateral circulation, and coronary slow flow.

Our study group included patients with high prevalence of cardiovascular risk factors including hyperlipidemia, diabetes mellitus, and COPD. All presented diffuse coronary lesions evaluated in coronary angiography. Therefore, it represents subjects with the highest cardiovascular risk. Probably, this may explain our result of non-significant difference between groups, though the absolute median PLR values were higher in the non-survivors' group. Also, in our analysis, post-operative lymphocyte count was higher in survivors. In the univariate analysis, PLR > 136 had a prognostic value for long-term mortality. Şaşkın et al. [93] noted a relationship between PLR and mortality but in a short postoperative period of 30 days. Indeed, there are no reports concerning the impact of PLR on longterm mortality after bypass surgery. Studies evaluating the usefulness of PLR in CABG patients reported its highest importance for prediction of acute kidney injury (AKI) [94] and post-operative atrial fibrillation [95]. Both complications are obviously associated with inflammatory response and domination of neutrophils engagement; therefore, NLR was also pointed out [96], as mentioned before. Navani et al. [97] however, in the large analysis of 1457 patients, did not confirm PLR significance for postoperative atrial fibrillation 
occurrence subgroups with PLR higher and lower than cut-off value of 86 derived from ROC analysis.

\subsection{Study Limitation}

Our study has some limitations and strengths. We analyzed a relatively large group of patients in the $5.3+/-1.7$-year period. The first limitation is that it is a single center study. However, it provided us with the possibility to collect a group of patients operated on by the same experienced surgical team with the same technique, which precludes variations among different centers. Secondly, we only evaluated all-cause mortality without profound analysis of causes of the deaths.

\section{Conclusions}

Hematological indices NLR and MLR can be regarded as significant predictors of all-cause long-term mortality after surgical revascularization performed with off-pump technique, especially in combination with demographical (age above 62 years) and echocardiographical parameters (preoperative left ventricle ejection fraction below $50 \%$ and postoperative below $45 \%$, respectively, and left ventricle diameter postoperative diameter above $48 \mathrm{~mm}$ ). Multivariable analysis revealed preoperative values of MLR $>0.2$ and postoperative values of NLR $>3.5$ as simple, reliable factors which may be applied into clinical practice for meticulous postoperative monitoring of patients with a higher risk of worse prognosis.

Author Contributions: Conceptualization, T.U. and A.O.-W.; methodology, T.U., A.O.-W., M.M. and M.R.; software, M.M.; validation, M.M.; formal analysis, M.M.; investigation, T.U, A.O-W., M.R., A.W.; resources, M.R., A.W.; data curation, M.R. and A.W.; writing—original draft preparation, T.U., A.O.-W.; writing - review and editing, E.S.-M., B.P. and M.J.; visualization, T.U., A.O.-W.; supervision, M.J.; project administration, T.U.; funding acquisition, B.P. and M.J. All authors have read and agreed to the published version of the manuscript.

Funding: This research received no external funding.

Institutional Review Board Statement: The study was conducted according to the guidelines of the Declaration of Helsinki, and approved by the Institutional Ethics Committee) of Poznan University of Medical Sciences (protocol code 914/21 and date of approval: 24 November 2021).

Informed Consent Statement: Not applicable.

Data Availability Statement: All data will be available under correspondence e-mail address for three years following the publication after request that would be justifiable.

Conflicts of Interest: The authors declare no conflict of interest.

\section{References}

1. Flora, G.D.; Nayak, M.K. A Brief Review of Cardiovascular Diseases, Associated Risk Factors and Current Treatment Regimes. Curr. Pharm. Des. 2019, 25, 4063-4084. [CrossRef]

2. Francula-Zaninovic, S.; Nola, I.A. Management of Measurable Variable Cardiovascular Disease' Risk Factors. Curr. Cardiol. Rev. 2018, 14, 153-163. [CrossRef] [PubMed]

3. Moriya, J. Critical roles of inflammation in atherosclerosis. J. Cardiol. 2019, 73, 22-27. [CrossRef]

4. Tabas, I.; Bornfeldt, K.E. Intracellular and Intercellular Aspects of Macrophage Immunometabolism in Atherosclerosis. Circ. Res. 2020, 126, 1209-1227. [CrossRef]

5. Mathis, D.; Shoelson, S.E. Immunometabolism: An emerging frontier. Nat. Rev. Immunol. 2011, 11, 81-86. [CrossRef]

6. Adamstein, N.H.; MacFadyen, J.G.; Rose, L.M.; Glynn, R.J.; Dey, A.K.; Libby, P.; Tabas, I.A.; Mehta, N.N.; Ridker, P.M. The neutrophil-lymphocyte ratio and incident atherosclerotic events: Analyses from five contemporary randomized trials. Eur. Heart J. 2021, 42, 896-903. [CrossRef] [PubMed]

7. Si, Y.; Fan, W.; Han, C.; Liu, J.; Sun, L. Atherogenic Index of Plasma, Triglyceride-Glucose Index and Monocyte-to-Lymphocyte Ratio for Predicting Subclinical Coronary Artery Disease. Am. J. Med. Sci. 2021, 362, 285-290. [CrossRef] [PubMed]

8. Yüksel, M.; Yıldız, A.; Oylumlu, M.; Akyüz, A.; Aydın, M.; Kaya, H.; Acet, H.; Polat, N.; Bilik, M.Z.; Alan, S. The association between platelet/lymphocyte ratio and coronary artery disease severity. Anatol. J. Cardiol. 2015, 15, 640-647. [CrossRef] [PubMed] 
9. Kose, N.; Akin, F.; Yildirim, T.; Ergun, G.; Altun, I. The association between the lymphocyte-to-monocyte ratio and coronary artery disease severity in patients with stable coronary artery disease. Eur. Rev. Med. Pharmacol. Sci. 2019, 23, 2570-2575.

10. Qiao, S.; Gao, W.; Guo, S. Neutrophil-Lymphocyte Ratio (NLR) for Predicting Clinical Outcomes in Patients with Coronary Artery Disease and Type 2 Diabetes Mellitus: A Propensity Score Matching Analysis. Ther. Clin. Risk Manag. 2020, 16, $437-443$. [CrossRef] [PubMed]

11. Qiu, Z.; Jiang, Y.; Jiang, X.; Yang, R.; Wu, Y.; Xu, Y.; Cheng, X. Relationship Between Platelet to Lymphocyte Ratio and Stable Coronary Artery Disease: Meta-Analysis of Observational Studies. Angiology 2020, 71, 909-915. [CrossRef] [PubMed]

12. Rossaint, J.; Margraf, A.; Zarbock, A. Perioperative Inflammation [Perioperative inflammation]. Anaesthesist 2019, 68, 421-427. [CrossRef] [PubMed]

13. Erichsen, J.H.; Forman, J.L.; Holm, L.M.; Kessel, L. Effect of anti-inflammatory regimen on early postoperative inflammation after cataract surgery. J. Cataract. Refract. Surg. 2021, 47, 323-330. [CrossRef]

14. Finnerty, C.C.; Mabvuure, N.T.; Ali, A.; Kozar, R.A.; Herndon, D.N. The surgically induced stress response. JPEN J. Parenter. Enteral Nutr. 2013, 37, 21S-29S. [CrossRef]

15. Forget, P.; Moreau, N.; Engel, H.; Cornu, O.; Boland, B.; De Kock, M.; Yombi, J.C. The neutrophil-to-lymphocyte ratio (NLR) after surgery for hip fracture (HF). Arch. Gerontol. Geriatr. 2015, 60, 366-371. [CrossRef]

16. Liu, X.; Wang, Y.; Fu, Z. Impact of enhanced recovery after surgery on postoperative neutrophil-lymphocyte ratio in patients with colorectal cancer. J. Int. Med. Res. 2020, 48, 300060520925941. [CrossRef]

17. Bekki, H.; Arizono, T.; Hama, D.; Inokuchi, A.; Hamada, T.; Imamura, R. Association of Postoperative Neutrophil Lymphocyte Ratio (NLR) and Monocyte Lymphocyte Ratio (MLR) with the Presence of Osteoporosis in Japanese Patients after Hip Fracture Surgery: A Retrospective Cohort Study. J. Osteoporos. 2021, 2021, 5524069. [CrossRef]

18. Cananzi, F.C.M.; Minerva, E.M.; Samà, L.; Ruspi, L.; Sicoli, F.; Conti, L.; Fumagalli Romario, U.; Quagliuolo, V.L. Preoperative monocyte-to-lymphocyte ratio predicts recurrence in gastrointestinal stromal tumors. J. Surg. Oncol. 2019, 119, 12-20. [CrossRef]

19. Kang, Y.; Zhu, X.; Lin, Z.; Zeng, M.; Shi, P.; Cao, Y.; Chen, F. Compare the Diagnostic and Prognostic Value of MLR, NLR and PLR in CRC Patients. Clin. Lab. 2021, 67, 78-89. [CrossRef]

20. Chen, J.H.; Zhai, E.T.; Yuan, Y.J.; Wu, K.M.; Xu, J.B.; Peng, J.J.; Chen, C.Q.; He, Y.L.; Cai, S.R. Systemic immune-inflammation index for predicting prognosis of colorectal cancer. World J. Gastroenterol. 2017, 23, 6261-6272. [CrossRef]

21. Schwartz, P.B.; Poultsides, G.; Roggin, K.; Howard, J.H.; Fields, R.C.; Clarke, C.N.; Votanopoulos, K.; Cardona, K.; Winslow, E.R. PLR and NLR Are Poor Predictors of Survival Outcomes in Sarcomas: A New Perspective From the USSC. J. Surg. Res. 2020, 251, 228-238. [CrossRef]

22. Kirmani, B.H.; Guo, H.; Ahmadyur, O.; Bittar, M.N. Long-term survival following on-pump and off-pump coronary artery bypass graft surgery: A propensity score-matched analysis. Eur. J. Cardio-Thorac. Surg. 2018, 56, 1147-1153. [CrossRef]

23. Napolitano, M.A.; Lee, K.B.; Rosenfeld, E.S.; Chen, S.W.; Sparks, A.D.; Nagy, C.D.; Greenberg, M.D.; Trachiotis, G.D. Long-Term Outcomes of Coronary Artery Bypass Grafting in Veterans with Ischemic Cardiomyopathy. Heart Surg. Forum 2020, 23, E323-E328. [CrossRef] [PubMed]

24. Kirmani, B.H.; Holmes, M.V.; Muir, A.D. Long-Term Survival and Freedom from Reintervention After Off-Pump Coronary Artery Bypass Grafting: A Propensity-Matched Study. Circulation 2016, 134, 1209-1220. [CrossRef] [PubMed]

25. Doenst, T.; Haverich, A.; Serruys, P.; Bonow, R.O.; Kappetein, P.; Falk, V.; Velazquez, E.; Diegeler, A.; Sigusch, H. PCI and CABG for Treating Stable Coronary Artery Disease: JACC Review Topic of the Week. J. Am. Coll. Cardiol. 2019, 73, 964-976. [CrossRef]

26. Mei, Y.Q.; Ji, Q.; Liu, H.; Wang, X.; Feng, J.; Long, C.; Cheng, B.; Xing, Y.; Li, J.; Hu, D. Study on the relationship of APACHE III and levels of cytokines in patients with systemic inflammatory response syndrome after coronary artery bypass grafting. Biol. Pharm. Bull. 2007, 30, 410-414. [CrossRef] [PubMed]

27. Uyar, I.S.; Onal, S.; Uysal, A.; Ozdemir, U.; Burma, O.; Bulut, V. Evaluation of systemic inflammatory response in cardiovascular surgery via interleukin-6, interleukin-8, and neopterin. Heart Surg. Forum 2014, 17, E13-E17. [CrossRef]

28. Rossaint, J.; Berger, C.; Van Aken, H.; Scheld, H.H.; Zahn, P.K.; Rukosujew, A.; Zarbock, A. Cardiopulmonary bypass during cardiac surgery modulates systemic inflammation by affecting different steps of the leukocyte recruitment cascade. PLoS ONE 2012, 7, e45738. [CrossRef]

29. Møller, C.H.; Steinbrüchel, D.A. Off-pump versus on-pump coronary artery bypass grafting. Curr. Cardiol. Rep. 2014, 16, 455-462. [CrossRef]

30. Matsuura, K.; Imamaki, M.; Ishida, A.; Shimura, H.; Fujita, H.; Niitsuma, Y.; Miyazaki, M. Low systemic vascular resistance state following off-pump coronary artery bypass grafting. Ann. Thorac. Cardiovasc. Surg. 2008, 14, 15-21.

31. Akila D'souza, B.; Vishwanath, P.; D'souza, V. Oxidative injury and antioxidants in coronary artery bypass graft surgery: Off-pump CABG significantly reduces oxidative stress. Clin. Chim. Acta 2007, 375, 147-152. [CrossRef] [PubMed]

32. Hadem, J.; Rossnick, R.; Hesse, B.; Herr, M.; Hansen, M.; Bergmann, A.; Kensah, G.; Maess, C.; Baraki, H.; Kümpers, P.; et al. Endothelial dysfunction following coronary artery bypass grafting: Influence of patient and procedural factors. Herz 2020, 45 , 86-94. [CrossRef] [PubMed]

33. Kerbaul, F.; Giorgi, R.; Oddoze, C.; Collart, F.; Guidon, C.; Lejeune, P.J.; Villacorta, J.; Gouin, F. High concentrations of N-BNP are related to non-infectious severe SIRS associated with cardiovascular dysfunction occurring after off-pump coronary artery surgery. Br. J. Anaesth. 2004, 93, 639-644. [CrossRef] [PubMed] 
34. Domingues, C.T.; Milojevic, M.; Thuijs, D.; van Mieghem, N.M.; Daemen, J.; van Domburg, R.T.; Kappetein, A.P.; Head, S.J. Heart Team decision making and long-term outcomes for 1000 consecutive cases of coronary artery disease. Interact. Cardiovasc. Thorac. Surg. 2019, 28, 206-213. [CrossRef]

35. ISCHEMIA Trial Research Group; Maron, D.J.; Hochman, J.S.; O’Brien, S.M.; Reynolds, H.R.; Boden, W.E.; Stone, G.W.; Bangalore, S.; Spertus, J.A.; Mark, D.B.; et al. International Study of Comparative Health Effectiveness with Medical and Invasive Approaches (ISCHEMIA) trial: Rationale and design. Am. Heart J. 2018, 201, 124-135.

36. Nording, H.; Baron, L.; Langer, H.F. Platelets as therapeutic targets to prevent atherosclerosis. Atherosclerosis 2020, 307, 97-108. [CrossRef]

37. Gómez-Moreno, D.; Adrover, J.M.; Hidalgo, A. Neutrophils as effectors of vascular inflammation. Eur. J. Clin. Investig. 2018, 48, e12940. [CrossRef]

38. Döring, Y.; Soehnlein, O.; Weber, C. Neutrophil Extracellular Traps in Atherosclerosis and Atherothrombosis. Circ. Res. 2017, 120, 736-743. [CrossRef]

39. Darbousset, R.; Thomas, G.M.; Mezouar, S.; Frère, C.; Bonier, R.; Mackman, N.; Renné, T.; Dignat-George, F.; Dubois, C.; Panicot-Dubois, L. Tissue factor-positive neutrophils bind to injured endothelial wall and initiate thrombus formation. Blood 2012 120, 2133-2143. [CrossRef]

40. Lievens, D.; von Hundelshausen, P. Platelets in atherosclerosis. Thromb Haemost. 2011, 106, 827-838.

41. Drechsler, M.; Megens, R.T.; van Zandvoort, M.; Weber, C.; Soehnlein, O. Hyperlipidemia-triggered neutrophilia promotes early atherosclerosis. Circulation 2010, 122, 1837-1845. [CrossRef] [PubMed]

42. Pamukcu, B.; Lip, G.Y.; Devitt, A.; Griffiths, H.; Shantsila, E. The role of monocytes in atherosclerotic coronary artery disease. Ann. Med. 2010, 42, 394-403. [CrossRef] [PubMed]

43. Woollard, K.J.; Geissmann, F. Monocytes in atherosclerosis: Subsets and functions. Nat. Rev. Cardiol. 2010, 7, 77-86. [CrossRef] [PubMed]

44. Ammirati, E.; Moroni, F.; Magnoni, M.; Camici, P.G. The role of T and B cells in human atherosclerosis and atherothrombosis. Clin. Exp. Immunol. 2015, 179, 173-187. [CrossRef]

45. de Boer, O.J.; Becker, A.E.; van der Wal, A.C. T lymphocytes in atherogenesis-functional aspects and antigenic repertoire. Cardiovasc. Res. 2003, 60, 78-86. [CrossRef]

46. Wigren, M.; Nilsson, J.; Kolbus, D. Lymphocytes in atherosclerosis. Clin. Chim. Acta 2012, 413, 1562-1568. [CrossRef]

47. Núñez, J.; Miñana, G.; Bodí, V.; Núñez, E.; Sanchis, J.; Husser, O.; Llàcer, A. Low lymphocyte count and cardiovascular diseases. Curr. Med. Chem. 2011, 18, 3226-3233. [CrossRef]

48. Weedle, R.C.; Da Costa, M.; Veerasingam, D.; Soo, A.W.S. The use of neutrophil lymphocyte ratio to predict complications post cardiac surgery. Ann. Transl. Med. 2019, 7, 778-788. [CrossRef]

49. Ramlawi, B.; Otu, H.; Mieno, S.; Boodhwani, M.; Sodha, N.R.; Clements, R.T.; Bianchi, C.; Sellke, F.W. Oxidative stress and atrial fibrillation after cardiac surgery: A case-control study. Ann. Thorac. Surg. 2007, 84, 1166-1172. [CrossRef]

50. Giakoumidakis, K.; Fotos, N.V.; Patelarou, A.; Theologou, S.; Argiriou, M.; Chatziefstratiou, A.A.; Katzilieri, C.; Brokalaki, H. Perioperative neutrophil to lymphocyte ratio as a predictor of poor cardiac surgery patient outcomes. Pragmat. Obs. Res. 2017, 8, 9-14. [CrossRef]

51. Green, J.; Bin Mahmood, S.U.; Mori, M.; Yousef, S.; Mangi, A.A.; Geirsson, A. Stability across time of the neutrophil-lymphocyte and lymphocyte-neutrophil ratios and associations with outcomes in cardiac surgery patients. J. Cardiothorac. Surg. 2019, 14, 164-171. [CrossRef]

52. Bath, J.; Smith, J.B.; Kruse, R.L.; Vogel, T.R. Association of neutrophil-to-lymphocyte ratio with outcomes after elective abdominal aortic aneurysm repair. J. Vasc. Nurs. 2019, 37, 213-220. [CrossRef] [PubMed]

53. Gawdat, K.; Legere, S.; Wong, C.; Myers, T.; Marshall, J.S.; Hassan, A.; Brunt, K.R.; Kienesberger, P.C.; Pulinilkunnil, T.; Legare, J.F. Changes in Circulating Monocyte Subsets (CD16 Expression) and Neutrophil-to-Lymphocyte Ratio Observed in Patients Undergoing Cardiac Surgery. Front. Cardiovasc. Med. 2017, 4, 12-23. [CrossRef] [PubMed]

54. Haran, C.; Gimpel, D.; Clark, H.; McCormack, D.J. Preoperative Neutrophil and Lymphocyte Ratio as a Predictor of Mortality and Morbidity After Cardiac Surgery. Heart Lung Circ. 2021, 30, 414-418. [CrossRef] [PubMed]

55. Silberman, S.; Abu-Yunis, U.; Tauber, R.; Shavit, L.; Grenader, T.; Fink, D.; Bitran, D.; Merin, O. Neutrophil-Lymphocyte Ratio: Prognostic Impact in Heart Surgery. Early Outcomes and Late Survival. Ann Thorac Surg. 2018, 105, 581-586. [CrossRef]

56. Squiccimarro, E.; Labriola, C.; Malvindi, P.G.; Margari, V.; Guida, P.; Visicchio, G.; Kounakis, G.; Favale, A.; Dambruoso, P.; Mastrototaro, G.; et al. Prevalence and Clinical Impact of Systemic Inflammatory Reaction After Cardiac Surgery. J. Cardiothorac. Vasc. Anesth. 2019, 33, 1682-1690. [CrossRef]

57. Paparella, D.; Parolari, A.; Rotunno, C.; Vincent, J.; Myasoedova, V.; Guida, P.; De Palo, M.; Margari, V.; Devereaux, P.J.; Lamy, A.; et al. The Effects of Steroids on Coagulation Dysfunction Induced by Cardiopulmonary Bypass: A Steroids in Cardiac Surgery (SIRS) Trial Substudy. Semin. Thorac. Cardiovasc. Surg. 2017, 29, 35-44. [CrossRef]

58. Aldemir, M.; Baki, E.D.; Adali, F.; Çarşanba, G.; Tecer, E.; Taş, H.U. Comparison of neutrophil:lymphocyte ratios following coronary artery bypass surgery with or without cardiopulmonary bypass. Cardiovasc. J. Afr. 2015, 26, 159-164. [CrossRef]

59. Urbanowicz, T.; Michalak, M.; Gąsecka, A.; Perek, B.; Rodzki, M.; Bociański, M.; Straburzyńska-Migaj, E.; Jemielity, M. Postoperative Neutrophil to Lymphocyte Ratio as an Overall Mortality Midterm Prognostic Factor following OPCAB Procedures. Clin. Pract. 2021, 11, 587-597. [CrossRef] 
60. Urbanowicz, T.K.; Michalak, M.; Gąsecka, A.; Olasińska-Wiśniewska, A.; Perek, B.; Rodzki, M.; Bociański, M.; Jemielity, M. A Risk Score for Predicting Long-Term Mortality Following Off-Pump Coronary Artery Bypass Grafting. J. Clin. Med. 2021, 10, 3032. [CrossRef]

61. Parlar, H.; Şaşkın, H. Are Pre and Postoperative Platelet to Lymphocyte Ratio and Neutrophil to Lymphocyte Ratio Associated with Early Postoperative AKI Following CABG? Braz. J. Cardiovasc. Surg. 2018, 33, 233-241. [CrossRef] [PubMed]

62. Taşoğlu, I.; Turak, O.; Nazli, Y.; Ozcan, F.; Colak, N.; Sahin, S.; Kavasoglu, K.; Genc, B.; Sert, D.; Karahan, M.; et al. Preoperative neutrophil-lymphocyte ratio and saphenous vein graft patency after coronary artery bypass grafting. Clin. Appl. Thromb Hemost. 2014, 20, 819-824. [CrossRef] [PubMed]

63. Ward, A.O.; Caputo, M.; Angelini, G.D.; George, S.J.; Zakkar, M. Activation and inflammation of the venous endothelium in vein graft disease. Atherosclerosis 2017, 265, 266-274. [CrossRef]

64. Baganha, F.; de Jong, A.; Jukema, J.W.; Quax, P.H.A.; de Vries, M.R. The Role of Immunomodulation in Vein Graft Remodeling and Failure. J. Cardiovasc. Transl. Res. 2021, 14, 100-109. [CrossRef] [PubMed]

65. Guida, G.; Ward, A.O.; Bruno, V.D.; George, S.J.; Caputo, M.; Angelini, G.D.; Zakkar, M. Saphenous vein graft disease, pathophysiology, prevention, and treatment. A review of the literature. J. Card Surg. 2020, 35, 1314-1321. [CrossRef] [PubMed]

66. Spartalis, M.; Spartalis, E.; Tzatzaki, E.; Tsilimigras, D.I.; Moris, D.; Kontogiannis, C.; Iliopoulos, D.C.; Voudris, V.; Siasos, G. Cardiac allograft vasculopathy after heart transplantation: Current prevention and treatment strategies. Eur. Rev. Med. Pharmacol. Sci. 2019, 23, 303-311.

67. Jackson, S.M.; Perry, L.A.; Borg, C.; Ramson, D.M.; Campbell, R.; Liu, Z.; Nguyen, J.; Douglas, N.; Kok, J.; Penny-Dimri, J. Prognostic Significance of Preoperative Neutrophil-Lymphocyte Ratio in Vascular Surgery: Systematic Review and Meta-Analysis. Vasc. Endovasc. Surg. 2020, 54, 697-706. [CrossRef]

68. Manzel, A.; Muller, D.N.; Hafler, D.A.; Erdman, S.E.; Linker, R.A.; Kleinewietfeld, M. Role of "Western diet" in inflammatory autoimmune diseases. Curr. Allergy Asthma Rep. 2014, 14, 404-417. [CrossRef]

69. Dominguez-Andres, J.; Netea, M.G. Long-term reprogramming of the innate immune system. J. Leukoc. Biol. 2019, 105, 329-338. [CrossRef]

70. Swirski, F.K.; Pittet, M.J.; Kircher, M.F.; Aikawa, E.; Jaffer, F.A.; Libby, P.; Weissleder, R. Monocyte accumulation in mouse atherogenesis is progressive and proportional to extent of disease. Proc. Natl. Acad. Sci. USA 2006, 103, 10340-10345. [CrossRef]

71. Nagareddy, P.R.; Murphy, A.J.; Stirzaker, R.A.; Hu, Y.; Yu, S.; Miller, R.G.; Ramkhelawon, B.; Distel, E.; Westerterp, M.; Huang, L.S.; et al. Hyperglycemia promotes myelopoiesis and impairs the resolution of atherosclerosis. Cell Metab. 2013, 17, 695-708. [CrossRef] [PubMed]

72. Ji, H.; Li, Y.; Fan, Z.; Zuo, B.; Jian, X.; Li, L.; Liu, T. Monocyte/lymphocyte ratio predicts the severity of coronary artery disease: A syntax score assessment. BMC Cardiovasc. Disord. 2017, 17, 90-98. [CrossRef] [PubMed]

73. Otsuka, F.; Kramer, M.C.; Woudstra, P.; Yahagi, K.; Ladich, E.; Finn, A.V.; de Winter, R.J.; Kolodgie, F.D.; Wight, T.N.; Davis, H.R.; et al. Natural progression of atherosclerosis from pathologic intimal thickening to late fibroatheroma in human coronary arteries: A pathology study. Atherosclerosis 2015, 41, 772-782. [CrossRef] [PubMed]

74. Zhou, Z.; Liang, M.; Wu, H.; Huang, S.; Weng, R.; Hou, J.; Wu, Z. Preoperative Lymphocyte-to-Monocyte Ratio as a Prognostic Predictor of Long-Term Mortality in Cardiac Surgery Patients: A Propensity Score Matching Analysis. Front. Cardiovasc. Med. 2021, 8, 639890-639900. [CrossRef]

75. Oksuz, F.; Elcik, D.; Yarlioglues, M.; Duran, M.; Ozturk, S.; Celik, I.E.; Kurtul, A.; Kilic, A.; Murat, S.N. The relationship between lymphocyte-to-monocyte ratio and saphenous vein graft patency in patients with coronary artery bypass graft. Biomark Med. 2017, 11, 867-876. [CrossRef]

76. Cai, M.; Liang, D.; Gao, F.; Hong, X.; Feng, X.; Yang, Y.; Wu, S.; Huang, W. Association of lymphocyte-to-monocyte ratio with the long-term outcome after hospital discharge in patients with ST-elevation myocardial infarction: A retrospective cohort study. Coron Artery Dis. 2020, 31, 248-254. [CrossRef]

77. Templeton, A.J.; Ace, O.; McNamara, M.G.; Al-Mubarak, M.; Vera-Badillo, F.E.; Hermanns, T.; Seruga, B.; Ocana, A.; Tannock, I.F.; Amir, E. Prognostic role of platelet to lymphocyte ratio in solid tumors: A systematic review and meta-analysis. Cancer Epidemiol. Biomark. Prev 2014, 23, 1204-1212. [CrossRef]

78. Nikolsky, E.; Grines, C.L.; Cox, D.A.; Garcia, E.; Tcheng, J.E.; Sadeghi, M.; Mehran, R.; Lansky, A.J.; Na, Y.; Stone, G.W. Impact of baseline platelet count in patients undergoing primary percutaneous coronary intervention in acute myocardial infarction (from the CADILLAC trial). Am. J. Cardiol. 2007, 99, 1055-1061. [CrossRef]

79. Iijima, R.; Ndrepepa, G.; Mehilli, J.; Bruskina, O.; Schulz, S.; Schömig, A.; Kastrati, A. Relationship between platelet count and 30-day clinical outcomes after percutaneous coronary interventions. Pooled analysis of four ISAR trials. Thromb Haemost. 2007, $98,852-857$.

80. Efe, E.; Kocayiğit, I.; Türker, P.M.; Murat, K.; Erkan, A.; Sedat, T.; Alper, Ç.; Necati, A.M.; Gökhan, V.M.; Bahri, A. Platelet-tolymphocyte ratio but not neutrophil-to-lymphocyte ratio predicts high on-treatment platelet reactivity in clopidogrel-treated patients with acute coronary syndrome. Indian J. Pharmacol. 2016, 48, 355-359. [CrossRef]

81. Zouridakis, E.G.; Garcia-Moll, X.; Kaski, J.C. Usefulness of the blood lymphocyte count in predicting recurrent instability and death in patients with unstable angina pectoris. Am. J. Cardiol. 2000, 86, 449-451. [CrossRef] 
82. Akboga, M.K.; Canpolat, U.; Yayla, C.; Ozcan, F.; Ozeke, O.; Topaloglu, S.; Aras, D. Association of Platelet to Lymphocyte Ratio With Inflammation and Severity of Coronary Atherosclerosis in Patients With Stable Coronary Artery Disease. Angiology 2016, 67, 89-95. [CrossRef] [PubMed]

83. Sari, I.; Sunbul, M.; Mammadov, C.; Durmus, E.; Bozbay, M.; Kivrak, T.; Gerin, F. Relation of neutrophil-to-lymphocyte and platelet-to-lymphocyte ratio with coronary artery disease severity in patients undergoing coronary angiography. Kardiol. Pol. 2015, 73, 1310-1316. [CrossRef] [PubMed]

84. Zhou, D.; Wang, G.; Fan, Y.; Wan, Z.; Liu, X. Platelet to lymphocyte ratio is associated with the severity of coronary artery disease and clinical outcomes of percutaneous coronary intervention in the Chinese Han population. Exp. Ther. Med. 2017, 13, 731-738. [CrossRef]

85. Açar, G.; Kalkan, M.E.; Avci, A.; Alizade, E.; Tabakci, M.M.; Toprak, C.; Özkan, B.; Alici, G.; Esen, A.M. The relation of plateletlymphocyte ratio and coronary collateral circulation in patients with stable angina pectoris and chronic total occlusion. Clin. Appl. Thromb Hemost. 2015, 21, 462-468. [CrossRef] [PubMed]

86. Azab, B.; Shah, N.; Akerman, M.; McGinn, J.T., Jr. Value of platelet/lymphocyte ratio as a predictor of all-cause mortality after non-ST-elevation myocardial infarction. J. Thromb Thrombolysis. 2012, 34, 326-334. [CrossRef]

87. Yildiz, A.; Yuksel, M.; Oylumlu, M.; Polat, N.; Akyuz, A.; Acet, H.; Aydin, M.; Ülgen, M.S. The Utility of the Platelet-Lymphocyte Ratio for Predicting No Reflow in Patients With ST-Segment Elevation Myocardial Infarction. Clin. Appl. Thromb Hemost. 2015, 21, 223-228. [CrossRef]

88. Çiçek, G.; Açıkgoz, S.K.; Bozbay, M.; Altay, S.; Uğur, M.; Uluganyan, M.; Uyarel, H. Neutrophil-lymphocyte ratio and plateletlymphocyte ratio combination can predict prognosis in patients with ST-segment elevation myocardial infarction undergoing primary percutaneous coronary intervention. Angiology 2015, 66, 441-447. [CrossRef]

89. Osadnik, T.; Wasilewski, J.; Lekston, A.; Strzelczyk, J.; Kurek, A.; Gonera, M.; Gawlita, M.; Reguła, R.; Bujak, K.; SzygułaJurkiewicz, B.; et al. The platelet-to-lymphocyte ratio as a predictor of all-cause mortality in patients with coronary artery disease undergoing elective percutaneous coronary intervention and stent implantation. J. Saudi Heart Assoc. 2015, 27, 144-151. [CrossRef] [PubMed]

90. Lee, Y.S.G.; Baradi, A.; Peverelle, M.; Sultani, R.; Adams, H.; Garlick, J.; Wilson, A.M. Usefulness of Platelet-to-Lymphocyte Ratio to Predict Long-Term All-Cause Mortality in Patients at High Risk of Coronary Artery Disease Who Underwent Coronary Angiography. Am. J. Cardiol. 2018, 121, 1021-1026. [CrossRef]

91. Cho, K.I.; Ann, S.H.; Singh, G.B.; Her, A.Y.; Shin, E.S. Combined Usefulness of the Platelet-to-Lymphocyte Ratio and the Neutrophil-to-Lymphocyte Ratio in Predicting the Long-Term Adverse Events in Patients Who Have Undergone Percutaneous Coronary Intervention with a Drug-Eluting Stent. PLoS ONE 2015, 10, e0133934.

92. Wang, Y.; Peng, Z. Prognostic value of platelet/lymphocyte ratio and CAMI-STEMI score for major adverse cardiac events in patients with acute ST segment elevation myocardial infarction after percutaneous coronary intervention: A prospective observational study. Medicine 2021, 100, e26942. [CrossRef] [PubMed]

93. Şaşkın, H.; Düzyol, Ç.; Özcan, K.S.; Aksoy, R.; Idiz, M. Preoperative Platelet to Lymphocyte Ratio Is Associated with Early Morbidity and Mortality after Coronary Artery Bypass Grafting. Heart Surg. Forum 2015, 18, E255-E262. [CrossRef]

94. Engin, M. Are Pre and Postoperative Platelet to Lymphocyte Ratio and Neutrophil to Lymphocyte Ratio Associated with Early Postoperative AKI Following CABG? Braz. J. Cardiovasc. Surg. 2020, 35, 239. [CrossRef] [PubMed]

95. Gungor, H.; Babu, A.S.; Zencir, C.; Akpek, M.; Selvi, M.; Erkan, M.H.; Durmaz, S. Association of Preoperative Platelet-toLymphocyte Ratio with Atrial Fibrillation after Coronary Artery Bypass Graft Surgery. Med. Princ. Pract. 2017, 26, 164-168. [CrossRef] [PubMed]

96. Parlar, H.; Arıkan, A.A.; Önmez, A. Dynamic Changes in Perioperative Cellular Inflammation and Acute Kidney Injury after Coronary Artery Bypass Grafting. Braz. J. Cardiovasc. Surg. 2021, 36, 354-364. [CrossRef]

97. Navani, R.V.; Baradi, A.; Colin Huang, K.L.; Jin, D.; Jiao, Y.; Nguyen, J.K.; Ellis, Z.C.; Newcomb, A.E.; Wilson, A.M. Preoperative Platelet-to-Lymphocyte Ratio Is Not Associated with Postoperative Atrial Fibrillation. Ann. Thorac. Surg. 2020, 110, 1265-1270. [CrossRef] 